\title{
Factores que inciden en las políticas de comercialización de yuca por microempresarias en el Mercado Municipal de Bilwi
}

\section{Steve Hemsly Bushey Wislot ${ }^{1}$ \\ Milton Rivera Zamora²}

\section{Resumen}

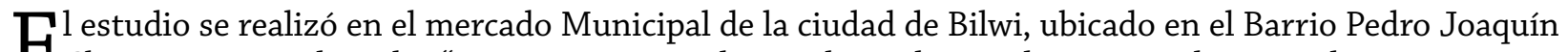
EChamorro; con el título: "Factores que inciden en las políticas de comercialización de yuca por microempresarias en el Mercado Municipal de Bilwi". El desarrollo de este estudio investigativo tuvo el propósito de analizar los factores, políticas, oferta, demanda y el costo beneficio que implementan las microempresarias; asimismo proponer alternativa de comercialización.

Tuvo un enfoque metodológico cualitativo, con elementos cuantitativo, debido a que se trata de describir qué acciones prácticas permiten que se comercialice la yuca en este mercado. Las variables identificadas en este estudio son: La incidencia de la comercialización de la yuca, la política de comercialización, la oferta, demanda y costo beneficio.

La población total estuvo conformada por 21 mujeres microempresarias, tomando como muestra el $62 \%$ equivalente a 13 microempresarias. Los resultados indican que la incidencia de la comercialización se hace en base a la forma que se oferta el producto, a la demanda al igual que se consideran las políticas de mayor importancia. En relación a los costos beneficios el estudio demostró que la venta por sacos está diferenciada, ya que influye el costo de adquisición y la temporada de compra y venta de la yuca.

Otro resultado refleja que las microempresarias carecen políticas de comercialización del producto yuca, razón por la cual se hacen diferentes propuestas para fortalecer el proceso de comercialización a las microempresarias, considerando el aporte de este estudio.

\footnotetext{
1 Lic. Administración de Empresa, Mención en Marketing. Correo electrónico: shbushey@gmail.com

2 Lic. En Administración de Empresa. tutor de la investigación. Correo electrónico: milton.kumi@gmail.com
} 


\section{Introducción}

El Mercado Municipal de Bilwi es uno de los mercados más antiguos de la ciudad, aquí se encuentran ubicadas 21 mujeres microempresarias que se dedican a la comercialización de yuca desde hace aproximadamente 20 años, actividad que realizan con el propósito de obtener ingresos económicos para solventar sus necesidades básicas y esta es la única alternativa de ingreso económico para la familia.

Las microempresarias comercializan otros rubros aparte de la venta de yuca como son: plátano, quequisque, coco, pescados, limones y granos como los frijoles, esta diversidad de productos que oferta es para ajustar el gasto diario de la familia ya que únicamente con la venta de un producto no se suple el gasto en que incurren. Para comercializar el producto utilizan la forma empírica, es decir no han sido capacitadas en temáticas sobre políticas de comercialización que les permita orientarlas para que de acuerdo a los costos de adquisición del producto, puedan obtener beneficios económicos y sociales producto de sus ventas.

Por tal razón se considera de mucha importancia y relevancia presentar el trabajo de investigación sobre "Factores que inciden en las políticas de comercialización de yuca por microempresarias en el Mercado Municipal de Bilwi”, tomando en cuenta los resultados que puede derivar de esta investigación en los aspectos socioeconómico, cultural y ambiental. Las variables principales de este estudio son factores y políticas de comercialización, oferta, demanda y el costo - beneficio que inciden en la comercialización de la yuca.

El tipo de estudio es mixto, descriptivo y de corte transversal, en la recopilación de información se aplicó guías de entrevista, encuesta y observaciones in situ, para el procesamiento de información se utilizó la técnica de palote, presentando los resultados en tablas matriciales tablas estadísticas.

Apoyado estos resultados se presentan las conclusiones y recomendaciones que podrán valer a las microempresarias, estudiantes, agentes externos con interés de apoyar en las actividades de comercialización de la yuca, y a su vez a las autoridades municipales, regionales e instituciones y organismo para implementar actividad de desarrollo socioeconómico, estimulando, modernizando a las microempresarias a un proceso de comercializar la yuca en una diversificación de oferta al consumidor, a la universidad que estudiantes realicen estudios de mayor profundidad sobre el tema.

\section{Revisión de literatura}

El trabajo investigativo consideró la revisión bibliografía orientada al análisis y discusión de resultado por lo cual se ha consultado veinte nueve referencias y se utilizaron a seis autores que fueron los que estuvieron más vinculados a fundamentar los resultados y que fueron citados en el marco teórico. Ver lista de referencia.

En el caso de Aguilar Antonio J. (2002), la contribución rerencia la comercialización del producto de yuca; Manfred M. A. (2017), aporta a la demanda y comercialización, de igual forma Boubeta B e Isabel A. (2009), menciona a las microempresaria, la oferta y factores de la comercialización; Costa R. (2007) sugiere las políticas, comercialización y precios del producto de yuca, de la misma forma tenemos que comenta Catie (2007) sobre los clientes, el consumo y precios al final a Mayra M. M (2004) define los costos, gastos y compra.

\section{Apertura de la información}

La idea inicial de esta investigación está vinculada con mi formación e interés en el producto de la yuca como materia de desarrollo en la región ya que es apetecidas por los pobladores, como también el gran alcance comercial que tiene tanto a nivel local, nacional e internacional y esto se pueden lograr obtener ingresos considerables y ser una fuente más de empleo en la región.

Estas razones orientaron el interés hacia las las percepciones de las microempresarias; asimismo, analizar la información primaria y secundaria relacionada a la comercialización de yuca dentro del radio en el mercado municipal de la ciudad de Bilwi. El estudio sobre la comercialización de yuca en el mercado municipal de Bilwi tiene una importancia social y comercial ya que las micro empresarias realizan comercialización de forma empírica; el cual la monografía compara y aporta temáticas para mejorar e implementar técnicas de mercadotecnia mediante uso de la materia con la finalidad de mejorar sus ingresos utilizando las diferentes propuestas como presentación al consumidor, alternativas de sub productos entre otros. 
Para esto se presentaron las variables que nos induzcan a informaciones y que aporten a nuestro conocimiento mediante sus conceptos: Organización, presentación, económica, cultural, social, estos elementos permitieron tener un mayor acercamiento a la averiguación de nuestros objetivos y plantear los conocimientos básicos para indagar a las micro empresarias, proveedores y otros con interés en el estudio de la comercialización de la yuca.

\section{Materiales y método}

Tipo de estudio: Cuantitativo, con algunos elementos cualitativos, descriptivo, retrospectivo y corte transversal, basado en los factores que inciden en las políticas de comercialización en el mercado de Bilwi.

Área de estudio: Mercado Municipal de Bilwi.

La duración del estudio: enero a Junio que corresponde a seis meses respectivamente, 2010.

Unidad de estudio: Mercado Municipal de Bilwi, específicamente en los lugares de venta de yuca (Calle de distribuidora "Auxiliadora Canales", calle central del mercado municipal y calle de la Iglesia Bautista).

Universo: 21 mujeres microempresarias del mercado municipal que se dedican a la comercialización de la yuca.

Muestra: La muestra estuvo representada por un $62 \%$ que equivale a 13 microempresarias, quienes fueron seleccionadas del universo que lo conforman 21 microempresarias

Muestreo: El muestreo es no probabilístico, es decir por conveniencia, ya que se tomó en cuenta a 13 microempresaria el cual es el $62 \%$ del universo como muestra del estudio de investigación. Es decir el universo de las microempresarias tiene las mismas posibilidades de ser tomado en cuenta para la indagación.

\section{Criterios de inclusión y exclusión}

Inclusión: Se tomó en cuenta a las Mujeres microempresarias del mercado municipal de Bilwi que comercializan yuca y que tuvieran dos años de dedicarse a la comercialización del producto en mención.

Exclusión: Se excluyó a Mujeres microempresarias del mercado municipal de Bilwi que no presentaran el criterio de selección tener dos años como mínimo en la comercialización de yuca.

Métodos y técnicas de recolección de información: encuestas, observación in situ.

Instrumentos para recopilación de información: guía de encuesta, guía de observación.

\section{Resultados y discusión}

\section{Factores que inciden en las políticas de co- mercialización de la yuca}

Los factores que inciden en la comercialización de la yuca según la opinión de las mujeres microempresarias, es la variabilidad de los precios, la presentación y calidad del producto. En cuanto a los precios las microempresaria manifestaban que la yuca se oferta al consumidor a precios entre $C \$, 10.00$ y 20.00 , que están a la vista del consumidor como una forma de atraer más al cliente y que este tome la decisión de adquirirlo según sus posibilidades económicas.

Por la importancia de este producto, el índice de comercialización en la ciudad es alto, ya que es un producto básico que complementa la dieta diaria de las familias, la cantidad demandada por parte de la población se debe a su múltiple uso que se le dan al producto, la forma más tradicional de consumo es acompañar en la hora del plato fuerte como bastimento y es preparado de diversas formas en el menú de la población porteña, cabe mencionar algunos de los variantes; el queque, refresco y el complemento principal del almuerzo.

Con base a esta opinión, Aguilar Antonio J. (2002) sostiene que, en la lucha por comercializar la yuca, los comerciante, productores se ven obligados a considerar la inestabilidad de los precios debido a la falta de planes continuos que permitan demostrar la capacidad de absorber el producto dentro de los mercados donde va ser consumido.

Relacionado los resultados con lo expresado por Aguilar (2002), se hace importante reconocer 
que este producto primeramente es ofertado por los comunitarios que producen y lo traen de las comunidades aledañas de la cabecera municipal, esta situación justifica que las microempresarias tengan que fijar otros precios que muchas veces no son homogéneos en los diferentes puntos de venta en este mercado, que si no necesariamente se encuentra el producto a un mismo precio.

Las encuestas manifestaban que el simple hecho que ellas tienen entre 10 a 30 años de comercializar este producto, se cuenta con la experiencia de satisfacer los gusto del consumidor, es por eso que consideran que, el tiempo que le ha dedicado a vender es otro de los factores que les ha permitido mantenerse en el mercado y practicar iniciativa de ventas que se traducen en estrategias y políticas de comercialización que les ha garantizado que los consumidores le sigan demando el producto.

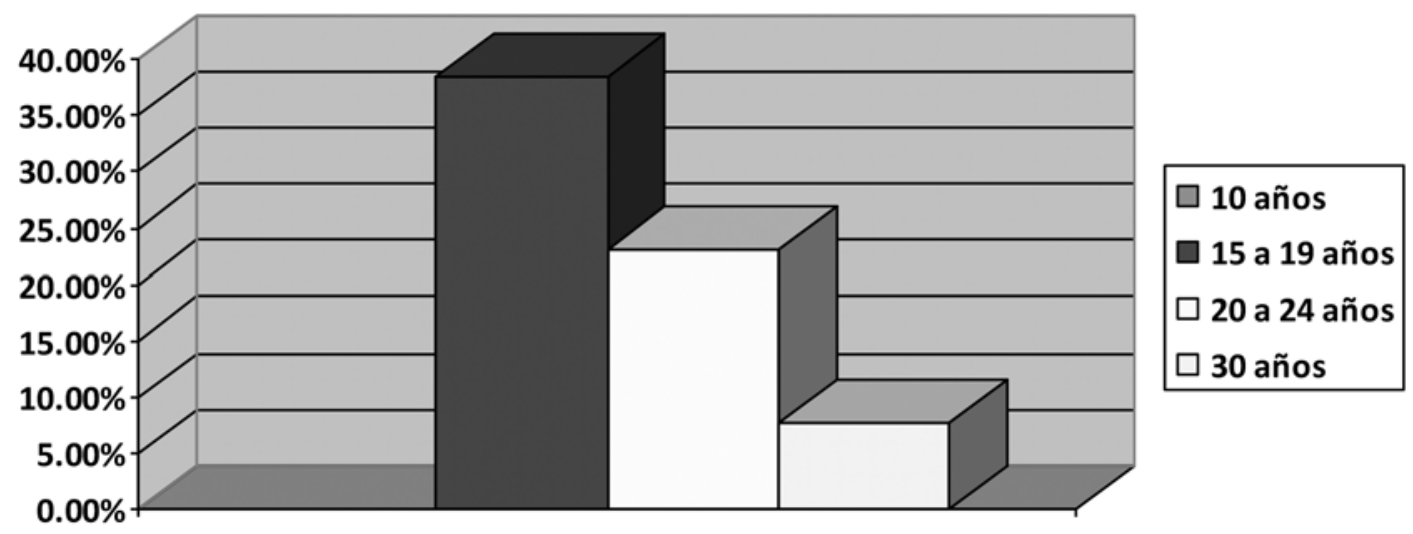

Figura $\mathrm{N}^{\circ}$ 1. Años de Comercializar yuca (2011).

Fuente: Tabla $\mathrm{N}^{\circ}$ 1. Enero, 2011.

Las opiniones presentadas mediante las encuestas demuestran que la comercialización de la yuca realizadas por las mujeres tiene una trayectoria de aproximada 20 a 24 años como promedio, lo que ha permitido a las microempresarias conozcan factores de forma empírica sin que hayan optados a una preparación empresarial, esto les han posibilitado que se realicen sus ventas y generen ingresos que son considerados como beneficios.

El factor tiempo en la comercialización este producto coincide con la opinión de Manfred M.A (2007), donde expresa que el tiempo para comercializar cualquier producto tiene que ver mucho con el análisis del entorno comercial que garantice que el comerciante identifique las formas correctas donde se va introducir y comercializar el producto mejorando así sus ingresos y que mantengan fijos el producto y los puntos de ventas.

\section{- Iniciativas de venta que les brindan a los consumidores}

LLas entrevistadas manifestaban que a medida que el tiempo pasa va surgiendo nuevas personas que hace esta actividad, razón por la cual ellas se ven obligadas a brindar otra iniciativa de venta a los clientes tales como:

1. Números de unidad de yuca por moño.

2. Tamaños.

3. Precio de venta.

4. La ubicación.

5. Regalía (regalan las yucas pequeñas).

En relación a la Calidad del producto las microempresarias la determina por: color, suavidad y fresco (tierno), ellas toman en cuenta y les explican a los consumidores la coloración que va dependiendo de la variedad esta puede ser blanca y amarillenta, al mismo tiempo esta coloración influye muchos en el tiempo de cocción que representa la suavidad porque muchas veces se les oferta la yuca fresca.

Las microempresaria opinan que, la comercialización de la yuca tiene que ver mucho con el gus- 
to, porque al momento de adquirir el producto prefieren muchas veces que sea tierna, porqué según ellos al momento de cocinarla es rápido (corto), la yuca más demanda y que cumple con exigencia del consumidor la yuca blanca llamado Molino, ya que esta tiene una estructura fina y de buen sabor.

Con respectos a la calidad del productos, Boubeta. B\& Isabel A. (2009) considera que, Como propietario de una pequeña empresa, cada uno de ellos son los responsable finales de la calidad del producto o servicio.

Pese a en marketing empresarial, la calidad de un producto es visualizado a través de una serie de factores como:

- Cantidad justa y deseada de producto.

- Rapidez de distribución de productos o de atención al cliente.

- Precio exacto (según la oferta y la demanda del producto).

- Calidad: Es el grado en el que un producto o servicio se ve reflejado en su diseño.

- Calidad de uso: El producto ha de ser fácil de usar, seguro, fiable.

Retomando las formas que las microempresarias determinan la calidad de la yuca, es importante destacar que, la calidad de un producto no se va a determinar solamente por parámetros puramente objetivos sino incluyendo las opiniones de un cliente que usa determinado producto o servicio.

Las consideración de la microempresaria con respecto a la calidad, el $100 \%$ de las entrevistadas manifestó que la calidad se demuestra con el tamaño que determina el rendimiento y la rentabilidad, el color que es un indicativo de apariencia y la suavidad porque la relacionan con el tiempo que se dilata para ser cocinada.

\section{- Forma de clasificar el producto}

La clasificación del producto adquiere dos aspectos importantes para las entrevistadas, ya que Un $77 \%$ expresa que, se clasifica de acuerdo al tamaño y un $23 \%$ opina que se clasifica por el color, siendo estos elementos básicos para que los consumidores demanden el producto.
A través de la observación se constató que dos elementos son tomados en cuenta cuando el consumidor hace la compra, siendo más frecuente la coloración porque es la mejor calidad y lo fresco que se pueda apreciar el producto esto se figura a simple vista.

- Calidad de servicios que brinda las microempresarias

Con respecto a la calidad del servicio para ofertar el producto, un $85 \%$ califican las condiciones que tienen actualmente de regular argumentando que ofrecen el producto en el piso de la calle y sobre un saco macen, esto hace que se exponga al sol y en algunas ocasiones bajo la lluvia, en cambio un $15 \%$ considera que las condiciones son buenas porque el productos es ofertado en pequeños tramos con mostrador y bajo techo, esta situación permite la protección del producto y por ende garantiza que el productos no se daña con facilidad.

Se constato que estas mujeres microempresaria que comercializan la yuca en muchos de los casos no tienen una infraestructura apropiada para poder oferta el producto por lo que han usado materiales de su alcance (sacos, colocado sobre la calle); sin embargo ante esta limitante de infraestructura ubican sus productos para que este a vista del consumidor y sea este el que decida hacer la compra.

Boubeta.B \& Isabel A. señala que las instalaciones y ubicación del negocios son elementos claves para que el comerciante puedan constar con mejores espacios y formas de ofertar el producto para que los consumidores se sienta atraídos por el espacio, distribución del productos y la comunicación con el comerciante.Precios (moño, tamaño, cantidad)

Las microempresarias consideran que el precio es unos de los retos que ha tenido que asumir después del huracán Félix, hubo escases de los productos; entonces, se incrementaron los precios pero también se buscaron otras iniciativas relacionadas con: el tamaño, cantidad. Generalmente la yuca se oferta en pequeños moños y estos se ponen a la vista del consumidor donde tienen la opción de hacer sus compras dependiendo de sus posibilidad económica, cada moño tiene entre cinco a siete raíces y un tamaño entre 4 a 12 pulgadas de largo, con diámetros de cinco a ocho centímetros aproximadamente. 
En relación al precios, Costa.R. (2007), refiere que es necesario que todo empresario defina previamente la política de precio, ya que este es considerado como, la cantidad que un consumidor desembolsa por un producto o servicio a cambio de la satisfacción que este le puede proporcionar.

\section{- Forma de ofertar el producto}

Con respecto a las formas que las microempresarias oferta la yuca, expresaron que; un $15.38 \%$ lo hacen en pequeños moños de raíces (yuca) que tienen un precio de $C \$ 5.00$, un $53.85 \%$ opinan que se hace moños un poco más grandes que tiene un precio de $C \$ 10.00$ y un 30.77\% expresa que también se les oferta moños que tiene un precios entre $C \$ 10$ a 20.00 respectivamente.

Para las microempresarias el producto se oferta de diferentes forma, esto está relacionado con los que establece la CATIE (2007), donde sostiene que es muy importante que la persona que comercializa cualquier producto establecen diferentes formas a los clientes con la intención que los clientes o consumidores se sienta satisfechos.

Estas ofertas son facilitadas a los consumidores de manera directa al contado, no existen políticas de créditos u otras formas para la adquisición de la yuca al consumidor, a través de la observación se determinó que la mayor presentación que adquiere mejor venta es la presentación de $C \$ 10.00$.

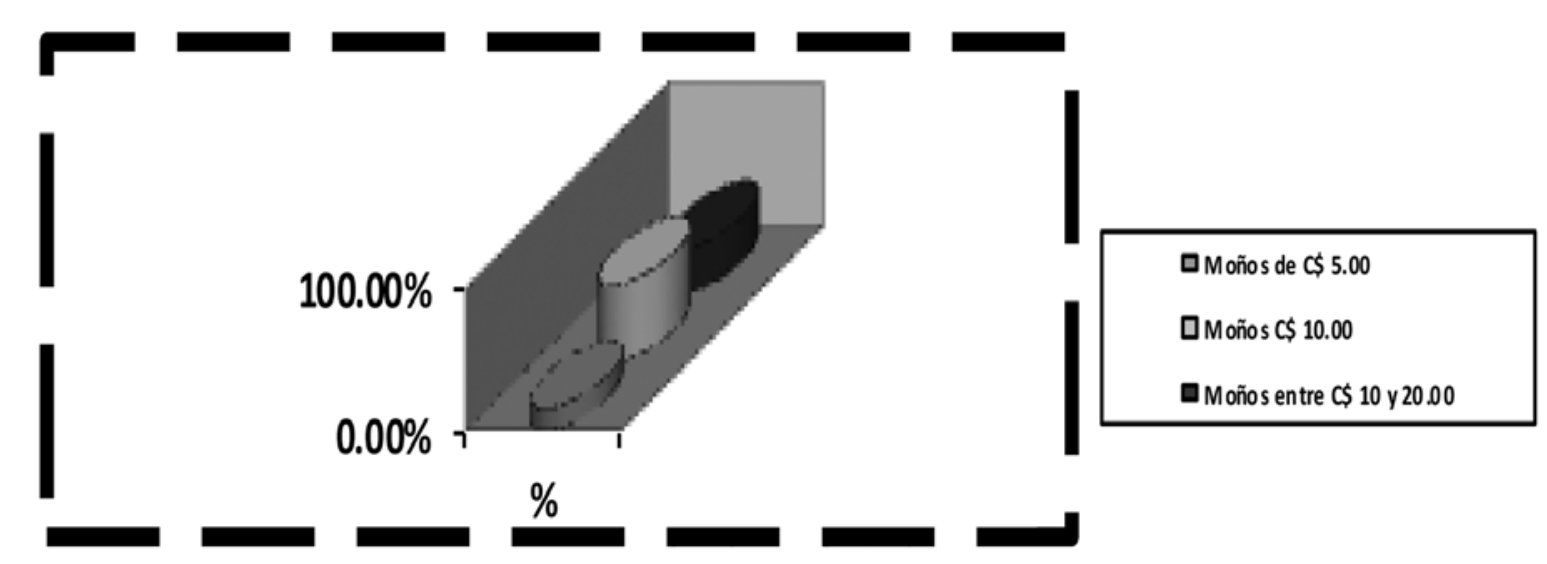

Figura $\mathrm{N}^{\circ}$ 2. Precio según Oferta.

Fuente: Tabla $\mathrm{N}^{\circ} 2$.

\section{Políticas de la oferta y demanda de la comercialización de yuca}

En la política oferta y demanda, se consideró importante conocer elementos que determina estos dos elementos tales como: la fijación de precios, adquisición del producto y los momentos de mayor demanda por los consumidores.

\section{- Fijación de precio}

Para el 100\% de las microempresaria el precio de la yuca, se fijan de acuerdo a la calidad y demanda del consumidor, esto es importante porque permite que se comercialice el producto y anticipe sus márgenes de ganancia de acuerdos a los costó de adquisición, otros de los elementos que se considera además de calidad y la demanda, es la presentación del producto en los diferentes puntos de venta. 
Costa R. (2007), sostiene que, la importancia y el significado que tiene la fijación de los precios del productos, es que todas las organizaciones lucrativas deben poner precio a sus productos o servicios. El precio es la cantidad de dinero que se cobra por un producto o servicio. De manera general, es la suma de los valores que el consumidor intercambia por los beneficios de tener o usar un producto o servicio.

Existen varios métodos para fijar los precios de los produtos o servicios entre los que se mencionan los siguientes:

1. Costes: En función de los costes de produción y de comercialización, a lo que añadiremos los gastos generales y los beneficios.

2. Demanda: Se fija el precio en función del valor que tiene el producto o servicio para el consumidor.

3. Competencia: Se toman como referencia los precios de la competencia.

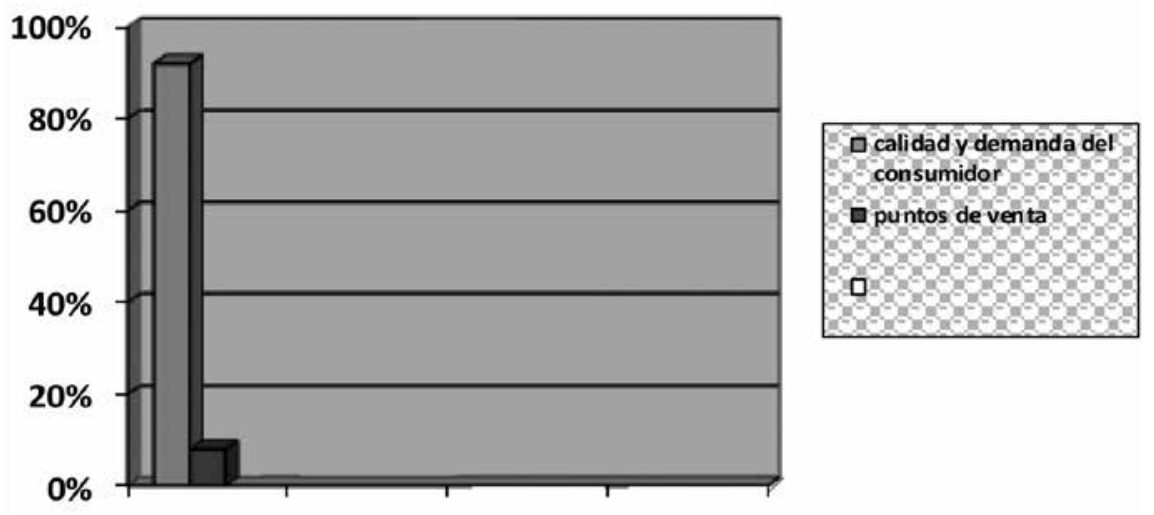

Figura $\mathrm{N}^{\circ}$ 3. Fijación de Precio.

Fuente: Tabla $\mathrm{N}^{\circ} 3$.

Durante la observación se determinó que las micro-empresarias tienen dos tipos de precios, de acuerdo a la presentación de $C \$ 10.00$ y $C \$ 20.00$; en algunos casos facilitan a sus clientes precio hasta de $C \$$ 5.00, esta opción se presenta cuando llega un consumidor y le declara su situación económica.

El precio que tiene mayores ventas es el de $C \$ 10.00$, está situación está relacionado con el hecho que población de Bilwi, en su mayoría son de bajo recursos es la presentación de su alcance económicos.

El precio de $C \$ 20.00$ es frecuentado en su compra por clientes que cuentan con un tipo de negocio como comediría y vígoron que por la actividad que desempeña hace que las compras además de ser numerosa sean más frecuente.

De acuerdo a este resultado, las mujeres micro-empresarias, existe una flexibilidad de oferta que está determinada de acuerdo a la demanda del consumidor, en función de estos se hacen diferentes presentaciones que permita que el consumidor no se vaya con las manos vacías.

Los precios que se ofertan según las micro empresarias son las más acorde para recuperar el costo del saco de la yuca ya que si se oferta a menor precio no se recuperara el monto de compra y no habrá un beneficio del mismo y al vender a mas alto el precio no se contara con clientes efectivos y varía mucho su demanda de adquisición, las experiencia de las micro empresarias empíricamente le manda a descifrar que los precios establecidos son las más idóneas para los consumidores y las más alcanzables. 


\section{- Políticas de precio que utilizan las microempresarias}

Con respecto a esta pregunta tres elementos son destacados por las mujeres micro-empresaria, los cuales están relacionados con: el tamaño, suavidad al momento del mercadeo y precio del saco de yuca.

A continuación de describen estos elementos considerados como políticas de precios por las entrevistadas:

- Las mujeres microempresarias consideran que un elemento determinante en la política de precio es el tamaño de la yuca, ya que en base al tamaño se selecciona la yuca y establecen los precios.

- La suavidad de la yuca es otro de los aspectos que las entrevistadas hacen mención, ya que al momento del cocimiento conserva la estructura y se dilata menos tiempo.

- El precio de adquisición del saco de yuca es considera una política de precio por las microempresarias tiene que ver con la deman$\mathrm{da}$, porque a menor demanda mayor el costo del saco de yuca.

Para Boubeta. B \& Isabel A. (2009) sostiene que los factores a tomar en cuenta a la hora de que preparar una política de precio, se debe considerar los siguientes:

- El precio y la calidad del servicio este ayuda a asentar marca y conseguir un buen nombre en la zona, ya que una buena política de precios ayuda a conseguir prestigio.

- Las instalaciones también son fundamentales. Ofrecer una buena imagen en decoración y contar con una buena ubicación son aspectos a tener en cuenta. Además, el hecho de que el ambiente sea lujoso y el servicio sea muy detallista pueden influir en que al cliente no le importe pagar más.

- El tipo de clientes que también puede influir a la hora de cuantificar los precios. Es decir, si nuestro potencial de clientes nos piden precios bajos, debemos buscar una buena relación calidad/precio. $\mathrm{Si}$, por el contrario, lo que más nos abunda son clientes que nos piden un trato personalizado y más exclusividad, debemos suponer que nuestros clientes están dispuestos a pagar por algo más especial.

\section{Costos y beneficios de la comercialización de yuca}

Los costos son todo valor incurrido para la obtención de algún bien, producto o servicio el cual es la suma de todo los pedidos que el demandante solicita y el beneficio es la utilidad que se tiene después de ofertar, es decir lo que queda después del costo invertido el excedente es el beneficio. Mayra M. M (2004). Para las microempresarias es el costo de compra y gastos de traslado que hacen en el momento de la adquisición del saco de yuca y al realizar su venta resta la diferencia el costo incidido y su diferencia es su beneficio Encuesta a Microempresarias (2010).

\section{Costo de comercialización de la yuca}

Las microempresaria expresan que, para determinar el costo que se obtiene de la compra por un saco de yuca, se toma en cuenta el precio de adquisición más el costo de traslado del punto de compra hasta los puestos de venta al consumidor, este sitúa que las micro empresarias del mercado municipal se traslada a la terminal donde llegado a su punto de comercialización.

En el siguiente cuadro dos se resume los costos beneficios que obtienen las microempresarias de la comercialización de la yuca basándose específicamente en el costo de un saco, sumado los costos de transporte de los puntos de compra a los puntos de ventas establecidos por ellas mismas.

Tabla: $\mathrm{N}^{\circ}$ 2. Costo de la comercialización de yuca

\begin{tabular}{|l|l|l|l|l|l|}
\hline $\begin{array}{c}\text { Compra } \\
\text { Venta }\end{array}$ & $\begin{array}{c}\text { Unidad } \\
\text { de } \\
\text { Medida }\end{array}$ & $\begin{array}{c}\text { Vendedora } \\
\# 1\end{array}$ & $\begin{array}{c}\text { Vendedora } \\
\text { \# 2 }\end{array}$ & $\begin{array}{c}\text { Vendedora } \\
\text { \# 3 }\end{array}$ & Media \\
\hline Compra & Saco & 235 & 335 & 435 & 335 \\
\hline Venta & Saco & 355 & 485 & 635 & 491 \\
\hline Ganancia & 120 & 150 & 200 & 156 \\
\hline
\end{tabular}

Fuente: Encuesta, 2011. 


\section{Relaciones:}

$$
\begin{aligned}
& C / B=1 \text { Indefinido } \\
& C / B<1 \text { No Rentable } \\
& C / B>1 \text { Rentable }
\end{aligned}
$$

\section{Fórmula:}

$\mathrm{C} / \mathrm{B}=\mathrm{I} / \mathrm{C}=\mathrm{B}$

\section{Cálculo de Costo Beneficio}

$$
\begin{aligned}
& \mathrm{C} / \mathrm{B}=\mathrm{I} / \text { Costo }=\mathrm{B} \\
& \mathrm{C} / \mathrm{B}=491 / 335 \\
& \mathrm{C} / \mathrm{B}=\mathbf{1 . 5}
\end{aligned}
$$

Mediante el cálculo de la relación de costo beneficio se considera que la comercialización de yuca que realiza las microempresarias del mercado municipal de Bilwi, es rentable ya que de cada córdobas invertido obtiene 0.5 centavo córdobas de ingreso es decir rentable. Con respecto a la rotación de venta por sacos las mujeres consideran que un saco de yuca es vendido en un día aproximadamente.

Los costos varían por la demanda en el momento y tiempo que llega el producto al mercado, el cual van desde $C \$ 200.00, C \$ 300.00$ hasta $C \$ 400.00 \mathrm{el}$ saco y el costo de traslado esta en $C \$ 35.00$ es decir, que si el saco tiene un valor promedio de $C \$ 300.00$ más el traslado el valor de un saco de yuca es de $C \$$ 335.00 .

La ganancia de un saco de yuca para las empresaria varían entre $C \$ 120.00 C \$ 150.00$ hasta $C \$$ 200.00 para un promedio de beneficio de $C \$ 156$ como promedio que se vende cada dos días.

El costo de la adquisición del saco de yuca es de $C \$ 335.00$ más, la suma de venta que es de $C \$ 156$ como promedio el ingreso bruto o bien la venta es de $C \$ 491$ por saco como promedio.

De acuerdo a los resultados se determina que la variación de los precios de adquisición se debe a un elemento importante, esta mujeres compran el producto a los comunitarios que lo traen de las comunidades estos tiene que ver mucho la época de producción (tiempo), lo que hace que la demanda sea alta o baja.

Con relaciona los resultados es importante que esta microempresarias vigilen muy de cerca sus costos de adquisición, es decir, si la producción y venta de su producto le cuesta más que a la competencia, tendrá que ponerle un precio más alto o limitar sus utilidades, lo cual la pondrá en desventaja frente a la competencia.

En base a los resultados de la determinación del costo - beneficio Costa. R. (2007) subraya que; Los costos determinan el precio mínimo del producto. La empresa desea fijar un precio que cubra tanto los costos de producción como los de distribución, que haga que el producto se venda y que los rendimientos de la inversión vayan de acuerdo con sus esfuerzos y los riesgos que corrió. Los costos de una empresa pueden ser un elemento muy importante para su estrategia de fijación de precios.

\section{Cantidad de yuca se vende diaria y por semana}

Considerando el comercio de la yuca es una actividad, se consideró importante indagar la cantidad de ventas diarias y por semanas, las entrevistadas respondieron que sus venta promedios de $C \$$ 250.00 diarios donde se toman en cuenta el precio son de $C \$ 10.00$ y $C \$ 20.00$ estos venden 25 moños con precios de $C \$ 10.00$ en el caso de que cada moño tenga un precio de $C \$ 20.00$ se vende un total de 20 moños diarios.

Las ventas semanales para las microempresaria tienen un promedio de $C \$ 1,500.00$. Los resultados demuestran que la venta de la yuca esta en dependencia de la oferta a menor costos de adquisición mayor la cantidad de venta, lo que significa que las mujeres tienen mayor ingreso en cambio a menor oferta es menor la demanda del producto por los consumidores y por ende menor el ingreso de las microempresarias.

Esquema $\mathrm{N}^{\circ}$ 1. Flujo diagrama de comercialización Yuca:

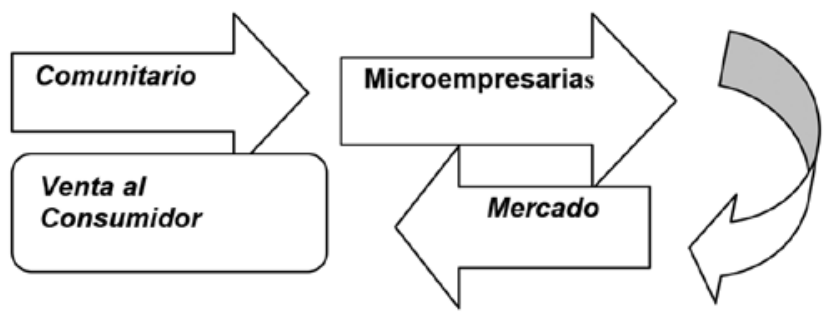




\section{Proponer políticas de Comercialización de yuca a microempresarias}

Para que las microempresarias puedan crear mayor potencial a la yuca como producto de consumo se deben establecer mecanismos de comercialización dentro y fuera del mercado a alcanzar otros objetivos empresariales rentables y no de subsistencia razón en la que se sustenta algunas políticas que a continuación se describen:

> Plaza

- El sitio donde está ubicado el puesto de venta.

- Higiene.

> Políticas de comercialización

- El ciclo de venta.

- Precios de acuerdo a la necesidad del consumidor.

- Precios según características del producto.

> Alternativas de diversificación como productos derribados

- Tajadas de la yuca.

- Afrecho (Alimentación para Animales).

- Elaboración de buña (refresco).

- Queque de yuca mejorado.

> Organización de las microempresarias

- Crear Asociación o cooperativas de microempresarias.

- Identificar los aliados con industrias nacionales para la comercialización.

- Definir las rutas de comercialización con los aliados.

- Crear las líneas de los productos derribados de la yuca con sus cadenas de comercialización.

\section{Cuadro $\mathrm{N}^{\circ}$ 3. Guía de procedimiento para las microempresarias}

\begin{tabular}{|c|c|c|c|}
\hline No. & Parámetro & Que deben Hacer & Como la deben Hacer \\
\hline 1 & Plaza & $\begin{array}{l}\text { Ubicarse en un espacio estratégico del mercado con mayor condición } \\
\text { para ofertar la yuca. }\end{array}$ & $\begin{array}{l}\text { Solicitar a la Municipalidad que brinden condiciones de oferta y ordenar los } \\
\text { puestos. }\end{array}$ \\
\hline 2 & $\begin{array}{l}\text { Políticas de } \\
\text { Comercialización }\end{array}$ & $\begin{array}{l}\text { Crear una la relación comercial con los comunitarios en donde les facilite } \\
\text { la yuca mediante demandas. }\end{array}$ & Organizadas y en coordinación \\
\hline 3 & $\begin{array}{l}\text { Alternativas de } \\
\text { Producción }\end{array}$ & Producir otros productos derivados de la yuca mediante las demandas. & $\begin{array}{l}\text { Buscar financiamiento y colaboración con el gobierno municipal y regional. } \\
\text { Elaborar y ofertar al mercado diversificación de producto. } \\
\text { Dar valor agregado. }\end{array}$ \\
\hline 4 & Organización & $\begin{array}{l}\text { Reuniones con la microempresarias para buscar espacios en las orga- } \\
\text { nizaciones locales e institucionales para mejorar sus capacidades como } \\
\text { microempresarias. }\end{array}$ & $\begin{array}{l}\text { Organizadas, Coordinar en Cooperativas y tocar puertas a los agentes de toma } \\
\text { decisiones en apoyo a mujeres microempresarias. }\end{array}$ \\
\hline
\end{tabular}




\section{Conclusiones}

De acuerdo al análisis de los resultados y los objetivos, se arriba a las siguientes conclusiones:

1. Las mujeres microempresarias del mercado municipal realizan la comercialización de la yuca de una forma empírica ya que desconocen las políticas de comercialización.

2. Los factores que inciden en la comercialización de la yuca son: el precio, la presentación y calidad del producto.

3. La calidad del productos es determinado por elementos físicos del producto tales como: (color, tamaño y suavidad/tierna).

4. La comercialización se hace de acuerdo la presentación con precios que van desde $C \$ 10.00$ hasta $C \$ 20.00$ y se oferta de acuerdo a las posibilidades económicas del consumidor.

5. La presentación de $C \$ 10.00$ es la mayor demandada por los consumidores.

6. El Costos Beneficios promedio que obtienen las microempresarias de la comercialización de la yuca en el Mercado Municipal es entre $C \$ 140.00$ a $C \$ 200.00$.

\section{Lista de referencia}

Aguilar,A.J (2002). El programa yuca en Panamá. Primera edición, Panamá.

Boubeta, B. y Isabel, A. (2009) Factores que restringen la comercialización de la yuca y la expansión de su produción. Habana Cuba.

Carrillo L. G, (1997) Comercialización de Yuca.

Córdobas G, (2007) Comercio de la yuca.

Crespo P. C. (1989). Metodología aplicada proyectos integrados de yuca., (primera edición), Habana Cuba.

Cock, J. (2009). Proyecto de desarrollo de la cadena de valor y comercialización agrícola.
Chemonic (2005). Cuenta reto del milenio Unitec states of América.

Díaz, F. A \& Parejo, A.J (1999). Políticas Económica segunda Edición.

Estudio de Oportunidades Comerciales de productos seleccionados Mercado. Managua - Nicaragua, 2005.

Fundación FAO (2005). La Economía Mundial de la yuca, hechos tenencia y perspectiva. Managua, Nicaragua.

FAO (2005). El comercio de la yuca fresca. 2. da edición. San Salvador, El Salvador. 2005.

Funtrell, Ch. (1995). Fundación de Mercadotecnia. Editorial Mc Graw Hill cuarta Edición.

Gámez, R. B. (2007). Desarrollo Agrícola e Industrial de la yuca en Nicaragua. 1era Edición, Managua, Nicaragua.

Grego,r J. S. (2004) .Centro internacional de Agricultura Tropical. Desarrollo de productos de raíces y tubérculos.

INTA (2005). Desarrollar el cultivo de yuca y su transformación es el objetivo de la cooperación bilateral, con la Empresa Brasileña de Pesquisa Agropecuaria (EMBRAPA), Managua, Nicaragua.

Kotler, Ph. \& Armstrong, G (1998). Fundamento de la Mercadotecnia. Cuarta edición S.A.

IICA (2005). El Instituto Interamericano de Cooperación para la Agricultura - Turialba, Costa Rica.

IICA (1996). Manual Técnico de la yuca.

IICA (2005). Yuca procesada rumbo al exterior. Managua, Nicaragua.

MERCASA (2001). Estudio de la Situación Actual de la Distribución Agroalimentaria en la República de El Salvador y Análisis de perfectibilidad de una unidad alimentaria en San Salvador. Madrid, julio 2001. 
Mayra M. M (2004). Precio y Mercado.

Mejoran niveles productivos y el precio de la yuca, versión electrónica [en línea] extraído el día, 22 de agosto de 2010 dehttp://www.cuentadelmilenio.org.ni/Comunicacion/Boletines\%20 Electronicos/Bol112/Bol_112.htm

Programa de Producción y Mercadeo de Yuca Valencia (2002).cda@fintrac.com, 2 de Junio 2002.

Pérez C. C (1989). Comercialización de la yuca.

Rodríguez, S. M. Y Ramos, R. (2007). El cultivo de la yuca en Cuba y Factores de Comercializacion. 1era edición, Habana, Cuba.

Rodríguez, A. M. y Carillo, L.G. (1987). El programa de yuca en México, 2da Edición, México, Distrito Federal.

Morán, G. R. A. \& Saavedra, S. D. A. (2000). Unidad Técnica de Desarrollo de Mercados y Agro negocios.

Manfred, M. A. T (2007). Políticas de comercialización productos. Tercera edición, 2007.

Políticas de Mercadeo versión electrónica, el día 13 de septiembre 2010. http://www.fao.org/ag/ ags/subjects/es/agmarket/marketpol.html.

Costa. R (2007). Estrategia de mercadeo y canales de distribución en el mercado, el día 15 de septiembre 2010.

http://es.slideshare.net/pasante/2-estrategias-de-mercadeo-y-canales-de-distribucin-en-el-mercado-canadiense

CATIE, 2007. Diagnóstico de Capacidadesy Estrategias de Proveedores de Servicios Empresariales en el Sector Forestal Tropical. Costa Rica. 